\title{
Prevalence and factors related to inappropriate referrals during intrapartum care - a mixed method study
}

Binyam Fekadu Desta ( $\sim$ binyamfe@gmail.com )

JSI Research and Training Institute, Inc https://orcid.org/0000-0002-2146-9516

Bethabile L. Dolamo

University of South Africa

\section{Research article}

Keywords: factors related to inappropriate referrals, intrapartum care, maternal and newborn care, prevalence, referral system

Posted Date: July 16th, 2020

DOl: https://doi.org/10.21203/rs.3.rs-39844/v1

License: (c) (i) This work is licensed under a Creative Commons Attribution 4.0 International License.

Read Full License 


\section{Abstract}

Background: Complications during delivery are responsible for half of all maternal deaths, one-third of stillbirths and a quarter of neonatal deaths. The care necessitates emergency care, and it is a known fact that reductions in maternal mortality and morbidity are not possible without an effective referral system. This study is aimed at measuring the prevalence of inappropriate referrals and identifying factors that contribute to it.

Methods: The study employed a sequential explanatory mixed research design. In the first phase, a retrospective cross-sectional quantitative study was done, 718 medical records were reviewed. The second phase involved a qualitative study of 26 key informants being interviewed.

Results: Three quarters of cases, $(74.23 \%$; $n=533)$, who visited the selected hospitals could have been managed at the health center level. Sixty-five percent of them, $(n=436)$, sought care at the hospital level with no referral from the lower level. Further analysis of the data showed no major difference as to the appropriateness of hospital level care in relation to age of mothers, previous medical and obstetrics history as well as danger signs at admission. On the other hand, number of parities, (chi-square $=9.3$; Pvalue $=0.010$ ), frequency of ANC, (chi-square $=6.7 ; p$-value $=0.037$ ) and the institution where ANC was sought, (chi-square $=12.9 ; \mathrm{p}$-value $=0.005$ ) were found to be associated with appropriateness of the case for hospital level care. Further inventory of the referred cases revealed that $33.2 \%$ of referred cases were appropriate for hospital level care. In addition, the qualitative study identified three major themes in relation to appropriateness of referrals: capability of identifying appropriate cases for referral, proper initiation of the referral process determining the outcome and functional cross-facility support platforms for better collaboration and coordination between facilities.

Conclusion: Referral, which is the coordination between facilities, requires readiness of the facilities at both ends as well as a transportation system. The governance system should also be strengthened to ensure the emergency management system in the country is effective.

\section{Background}

An ambitious target for the reduction of maternal and new-born mortality has been set in the Sustainable Development Goals. Every country, by 2030 , is expected to contribute to the reduction of the global maternal mortality ratio to less than 70 per 100000 live births and reduce neonatal mortality to at least as low as 12 per 1000 live births (1). In general, delivery complications are responsible for half of all maternal deaths, one-third of stillbirths and a quarter of neonatal deaths (2). In addition, reducing maternal mortality and morbidity remains a major challenge in Sub-Saharan Africa as the availability and quality of care is heterogeneous and often, inadequate (3). 
Clinical care, beginning at the start of labor, to the early post-natal period, can be provided either as routine or emergency care. Routine care includes identification, monitoring and management of noncomplicated pregnancies and deliveries. Emergency care on the other hand, includes a number of stabilizing and life-saving clinical interventions, and the timely arrangement for effective referral of mothers to higher levels of care (4). Both processes have two preconditions - seeking skilled care from facilities and delivering high quality care to prevent and address complications that may arise (5). On top of the health service outcomes, poor quality of clinical care and mistreatment discourage women from facility based delivery, encourage them to bypass facilities with a bad reputation, or delay seeking care and then arrive in critical condition (6).

The referral chain model proposed by Jahn et al. which has three main components: sender, transport and receiver might better explain what is expected from the health system. At the sender facility, factors such as risk assessment, availability of referral guidelines, quality of care, clinical judgement, and availability of transportation are important factors. At the receiver facility, quality of care, financial accessibility and preferential treatment are important factors to consider in the referral chain model (7).

Given the nature of the emergency care system, it is a known fact that reductions in maternal mortality and morbidity are not possible without an effective referral system (7). The coordination between the lower level facilities and that of higher levels for appropriate care usually lacks strength. As per the standard care procedure, clients need to be examined and provided with immediate management at the primary level facility (sender), before being sent to another facility, (receiver). However, the practices on the ground show that these procedures are not followed. Clients are either just examined or are made to attempt normal delivery and sent to referral facilities without any management. In addition, clients usually approach the facility directly due to either proximity, familiarity with the facility or through advice by others (8).

In settings where there are weak referral structures, due to inappropriate referral practices, hospital level maternal and new-born mortality is often higher (4). Ineffective referral systems result in negative patient experiences, unnecessary high costs and are a burden on health system (9). The appropriateness of the referrals can be defined by their distinct attributes - referral necessity, referral destination and referral quality (10). This study is aimed at measuring the prevalence of inappropriate referrals and identifying factors that contribute to it.

\section{Methods}


The study employed a sequential explanatory mixed research design (11). A quantitative retrospective cross-sectional study using medical records in the first phase (12). In relation to the study's objective, registers available at primary hospitals to document selected backgrounds, care elements and outcome of the services provided at delivery were reviewed. In the second phase of this study, the researchers considered key informant interviews as a primary method of data collection (13). Key informant interviews were conducted using face-to-face, and one-on-one interviews using very few open-ended questions intended to illicit views and ideas from participants of the study (11).

\section{STUDY SETTING}

The health sector in Ethiopia has introduced a three-tier health care delivery system which is characterized by a first level of a woreda/district health system comprising of a primary hospital, (with a population coverage of $60,000-100,000$ people), health centers (1/15,000-25,000 population coverage) and their satellite health posts (1/3,000-5,000 population coverage) that are connected to each other through a referral system, (Federal Ministry of Health, 2010:4). Hence, this study considered the system at the primary level of care - primary hospitals and health centers, and their relationship to provide services related to maternal and new-born care.

Multistage sampling, which is a variant of cluster sampling was employed by the researcher (14). The first step was to randomly select one of the four clusters within the large regional states in Ethiopia by lottery method. After selecting the region, the second stage was forming strata of primary hospitals. All primary hospitals from the region were arranged considering their performance of institutional delivery based on the previous full fiscal year. Taking the median of performance, the primary hospitals formed two strata - high performing, (above the median) and low performing, (below the median). Then, hospitals in each stratum were randomized and one primary hospital from each stratum was selected randomly.

\section{Quantiative study}

\section{Sample and Sampling}

The study population was drawn from the primary hospital records. Mothers who sought delivery care were considered as a reference population. A list of mothers who visited the primary hospitals within the period from July 08, 2017 to July 07, 2018 were registered in the case extraction sheet. The sample size 
for this study was determined using single population proportion formula. The study considered the following assumptions: hospital level delivery as $26.2 \%(p=0.262)(15)$. Level of significance at $5 \%(a=$ $0.05), \mathrm{z}$ a/2 $=1.96$ and margin of error to be $4 \%(\mathrm{~d}=0.04)$. Adding the design effect of 1.5 makes the total sample size and $10 \%$ of non-response rate. The total sample size was 766 , (16). For the delivery case reviews, this number was then proportionally distributed to the selected two primary hospitals.

The data collection also employed inclusion and exclusion criteria. The inclusion criteria included,

- Mothers residing in the woreda and

- Mothers who visited the hospitals for delivery care

The exclusion criteria included:

- Mothers that are residing in the kebeles (villages) which do not have catchment health centers

- Mothers with no record of kebeles (villages)

- No patient chart attached to the records

\section{Data management}

A data collection format which includes the pre-identified variables: summary of referral information, description of the cases presented, diagnosis of cases, and outcome of care from the facility registers were developed by the researcher (Supplemental file 1). Then, data collectors who have completed at least a first degree in health studies were selected and deployed in each primary hospital. Before the data collection, the data collectors were trained by the lead researcher on the components of the data sheet as well as the importance of each variable. The data collection process was supervised by the lead researcher. In addition, two health workers who are trainers of Basic Emergency Obstetrics and Newborn Care (BEmONC), independently reviewed the collected information and decided on whether the case could have been managed at health center based on the national guidelines or not. When there was a difference between the two reviewers, the lead researcher mediated a discussion to reach on consensus. Once the data were cleaned, using Stata version 14, a stepwise approach to data analysis was employed for descriptive analysis and running of a chi-square test to identify factors which contributed for appropriateness of referrals. 


\section{Qualitative method - Key Informant Interviews}

Participants of the qualitative research were purposefully selected based on the assumption that they understand the issues and are able to respond better to the research questions (17). Three of the most senior health professionals working in the maternal and child health $(\mathrm{MCH})$ departments were recruited for this phase. However, as the experiences differ within each type of health facility, a sufficient number of participants from each level of health facilities were included in the study (18). The total sample size was finally determined by the saturation level and thus a total of 26 individuals were included in this study.

The interview process was guided by an interview guide (Supplemental file 2) which included basic information about the research, introduction, opening questions, content questions, use of probes, and closing instructions. As advised by Creswell and Creswell, the number of questions were limited to between 5 to 10 (11). In addition, the kind of questions included in the protocol were based on the theoretical model, research question and issues raised during the first phase of the study (17). The data collection instrument was translated into Amharic, which is the local language for the interviews. A language expert was used to translate the tool after which an independent expert translated the Amharic version back into English to check whether the concepts were lost in the translation process.

Health professionals working at health centers and primary hospitals were interviewed by the researcher and field assistants. The data collection instrument was administered through discussion with participants. The interview was audio recorded and the interviewer also took notes during the interview process (18).

The qualitative data analysis required sequential steps to be followed from specific to general analysis. The data analysis also began in the field while the data collection occurred (17). The initial steps included transcribing and organizing the data and scanning and reviewing the data set to understand the general meaning, tones and quality of the data set (11). For the detailed analysis, ATLAS.ti was used to organize the data and analyze it further. First, a couple of interviews with health professionals were read to develop a coding chart. The coding book considers both predetermined codes (from the conceptual framework) and emerging codes (11) and successive transcripts were read line-by-line and coded for recurrent concepts. Then, the coding process led to generation of descriptions and themes.

\section{ETHICAL CONSIDERATIONS}


The proposal, survey methods and tools which guided this research were submitted for review and approval by the UNISA Department of Health Studies' Higher Degrees Committee. Then, the letter from the review board along with the proposal was submitted to the regional health bureau. The regional health bureau reviewed the proposal and wrote letters to selected sites. A permission to utilize the medical records was granted by the regional health bureau and each institution. For the key informant interviews, study participants who are older than 18 years were included and informed about the purpose and duration of the interviews and verbal consent was secured.

\section{Results}

\section{Quantitative findings}

A total of 718 cases, (94\% of response rate) which fulfilled the inclusion criteria were included in this study. The study found that many deliveries which should have been managed at health center level were managed by hospitals. Three quarters of cases, $(74.23 \% ; n=533)$ who visited the selected hospitals could have been managed at the health center level. The descriptive analysis showed that close to twothirds of inappropriate cases for hospitals were young, (15 to 25 years old) and had more than four ANC visits. Close to half of the inappropriate referrals reported one to three live deliveries and had their ANC visits at a catchment health center of the primary hospital. The analysis of the data showed no major difference as to the appropriateness of hospital level care in relation to age of mothers, previous medical and obstetrics history as well as danger signs at admission. On the other hand, number of parities (chisquare $=9.3 ; p$-value $=0.010$ ), frequency of ANC, (chi-square $=6.7 ; p$-value $=0.037$ ) and timing of seeking ANC, (chi-square $=12.9 ; \mathrm{p}$-value $=0.005$ ) were found to be associated with appropriateness of the case for hospital level care.

The study also found close to two-thirds of the cases which should have been managed at health centers were self-referrals. The findings also demonstrated a significant association with appropriateness of referrals at chi-square $=13.3$ and $p$-value of $<0.001$, (Table 1$)$. Moreover, further inventory of the referred cases revealed that approximately $33.2 \%$ of referred cases were appropriate for hospital level care. The comparative analysis showed that distance to hospitals, (chi-square $=9.3 ; p$-value $=0.010$ ) has an influence on the appropriateness of referrals. In addition, use of referral slips, (chi-square =17.97; p-value $<0.001$ ) and ability to determine the cause, (chi-square $=6.4 ; p$-value $=0.011$ ) were associated with appropriateness of referrals. The latter is directly related to the competence of the provider as well the availability of the necessary gadgets at the health center level which boosts the confidence of providers to select appropriate cases for referrals. 
Table 1

Description of factors related to appropriateness of referral status

\begin{tabular}{|c|c|c|c|c|c|c|c|c|}
\hline \multirow[t]{2}{*}{ Variables } & \multicolumn{4}{|c|}{$\begin{array}{l}\text { Can this case be managed at } \\
\text { the health center level? }\end{array}$} & \multirow{2}{*}{\multicolumn{2}{|c|}{ Total }} & \multirow[t]{2}{*}{$\begin{array}{l}\text { Chi- } \\
\text { square }\end{array}$} & \multirow[t]{2}{*}{$\begin{array}{l}\mathrm{P} \text { - } \\
\text { value }\end{array}$} \\
\hline & \multicolumn{2}{|l|}{ Yes } & \multicolumn{2}{|l|}{ No } & & & & \\
\hline \multicolumn{9}{|c|}{ Age group of mothers } \\
\hline $15-25$ & 333 & $63 \%$ & 105 & $57 \%$ & 438 & $62 \%$ & 3.10 & 0.211 \\
\hline $26-35$ & 181 & $34 \%$ & 71 & $39 \%$ & 252 & $36 \%$ & & \\
\hline$>35$ & 11 & $2 \%$ & 7 & $4 \%$ & 18 & $3 \%$ & & \\
\hline Total & 525 & $100 \%$ & 183 & $100 \%$ & 708 & $100 \%$ & & \\
\hline \multicolumn{9}{|l|}{ Number of parities } \\
\hline Nullipara & 197 & $39 \%$ & 65 & $37 \%$ & 262 & $39 \%$ & 9.29 & 0.010 \\
\hline Para 1 to 3 & 240 & $48 \%$ & 73 & $41 \%$ & 313 & $46 \%$ & & \\
\hline Para 4 and above & 65 & $13 \%$ & 40 & $22 \%$ & 105 & $15 \%$ & & \\
\hline Total & 502 & $100 \%$ & 178 & $100 \%$ & 680 & $100 \%$ & & \\
\hline \multicolumn{9}{|c|}{$\begin{array}{l}\text { Any pregnancy danger signs } \\
\text { at admission }\end{array}$} \\
\hline Yes & 26 & $5 \%$ & 10 & $5 \%$ & 36 & $5 \%$ & 0.05 & 0.830 \\
\hline No & 494 & $95 \%$ & 175 & $95 \%$ & 669 & $95 \%$ & & \\
\hline Total & 520 & $100 \%$ & 185 & $100 \%$ & 705 & $100 \%$ & & \\
\hline \multicolumn{9}{|c|}{ Previous obstetrics problems } \\
\hline Yes & 106 & $20 \%$ & 37 & $20 \%$ & 143 & $20 \%$ & 0.0005 & 0.982 \\
\hline No & 426 & $80 \%$ & 148 & $80 \%$ & 574 & $80 \%$ & & \\
\hline Total & 532 & $100 \%$ & 185 & $100 \%$ & 717 & $100 \%$ & & \\
\hline \multicolumn{9}{|c|}{ Previous medical problems } \\
\hline Yes & 90 & $17 \%$ & 34 & $18 \%$ & 124 & $17 \%$ & 0.21 & 0.643 \\
\hline No & 443 & $83 \%$ & 151 & $82 \%$ & 594 & $83 \%$ & & \\
\hline Total & 533 & $100 \%$ & 185 & $100 \%$ & 718 & $100 \%$ & & \\
\hline \multicolumn{9}{|c|}{$\begin{array}{l}\text { Number of ANC follow up } \\
\text { visits }\end{array}$} \\
\hline No ANC visits & 10 & $3 \%$ & 3 & $4 \%$ & 13 & $4 \%$ & 6.70 & 0.035 \\
\hline
\end{tabular}




\begin{tabular}{|c|c|c|c|c|c|c|c|c|}
\hline \multirow[t]{2}{*}{ Variables } & \multicolumn{4}{|c|}{$\begin{array}{l}\text { Can this case be managed at } \\
\text { the health center level? }\end{array}$} & \multirow{2}{*}{\multicolumn{2}{|c|}{ Total }} & \multirow[t]{2}{*}{$\begin{array}{l}\text { Chi- } \\
\text { square }\end{array}$} & \multirow[t]{2}{*}{$\begin{array}{l}\mathrm{P} \text { - } \\
\text { value }\end{array}$} \\
\hline & Yes & & No & & & & & \\
\hline $1-3$ ANC visits & 96 & $32 \%$ & 12 & $17 \%$ & 108 & $29 \%$ & & \\
\hline $4+$ ANC visits & 193 & $65 \%$ & 57 & $79 \%$ & 250 & $67 \%$ & & \\
\hline Total & 299 & $100 \%$ & 72 & $100 \%$ & 371 & $100 \%$ & & \\
\hline \multicolumn{9}{|l|}{ Institution of ANC follow up } \\
\hline In this hospital & 52 & $29 \%$ & 6 & $14 \%$ & 58 & $26 \%$ & 12.90 & 0.005 \\
\hline In the referring facility & 29 & $16 \%$ & 17 & $40 \%$ & 46 & $21 \%$ & & \\
\hline $\begin{array}{l}\text { From the catchment health } \\
\text { center }\end{array}$ & 88 & $49 \%$ & 17 & $40 \%$ & 105 & $47 \%$ & & \\
\hline Other institutions & 10 & $6 \%$ & 3 & $7 \%$ & 13 & $6 \%$ & & \\
\hline Total & 179 & $100 \%$ & 43 & $100 \%$ & 222 & $100 \%$ & & \\
\hline \multicolumn{9}{|l|}{ Referral status } \\
\hline Referred & 187 & $35.1 \%$ & 93 & $50.3 \%$ & 280 & $40.0 \%$ & 13.31 & $<.001$ \\
\hline Self-referral & 346 & $64.9 \%$ & 92 & $49.7 \%$ & 438 & $60.0 \%$ & & \\
\hline Total & 533 & $100 \%$ & 185 & $100 \%$ & 718 & $100 \%$ & & \\
\hline \multicolumn{9}{|l|}{$\begin{array}{l}\text { Time it takes to reach the } \\
\text { primary hospital by } \\
\text { ambulance (min) }\end{array}$} \\
\hline$<20$ & 36 & $19.3 \%$ & 13 & $14.0 \%$ & 49 & $17.5 \%$ & 9.28 & 0.010 \\
\hline $30-45$ & 97 & $51.9 \%$ & 36 & $38.7 \%$ & 133 & $47.5 \%$ & & \\
\hline$>45$ & 54 & $28.9 \%$ & 44 & $47.3 \%$ & 98 & $35.0 \%$ & & \\
\hline Total & 187 & $100 \%$ & 93 & $100 \%$ & 280 & $100 \%$ & & \\
\hline \multicolumn{9}{|l|}{ Referral slip attached } \\
\hline Yes & 100 & $53.7 \%$ & 74 & $79.6 \%$ & 174 & $62.1 \%$ & 17.97 & $<.001$ \\
\hline No & 87 & $46.3 \%$ & 19 & $20.4 \%$ & 106 & $37.9 \%$ & & \\
\hline Total & 187 & $100 \%$ & 93 & $100 \%$ & 280 & $100 \%$ & & \\
\hline \multicolumn{9}{|l|}{ Cause for referral established } \\
\hline Yes & 62 & $60.2 \%$ & 55 & $78.6 \%$ & 117 & $67.6 \%$ & 6.43 & 0.011 \\
\hline
\end{tabular}




\begin{tabular}{|c|c|c|c|c|c|c|c|c|}
\hline \multirow[t]{2}{*}{ Variables } & \multicolumn{4}{|c|}{$\begin{array}{l}\text { Can this case be managed at } \\
\text { the health center level? }\end{array}$} & \multirow[t]{2}{*}{ Total } & & \multirow[t]{2}{*}{$\begin{array}{l}\text { Chi- } \\
\text { square }\end{array}$} & \multirow[t]{2}{*}{$\begin{array}{l}\mathrm{P}- \\
\text { value }\end{array}$} \\
\hline & Yes & & No & & & & & \\
\hline No & 41 & $39.8 \%$ & 15 & $21.4 \%$ & 56 & $32.4 \%$ & & \\
\hline Total & 103 & $100 \%$ & 70 & $100 \%$ & 173 & $100 \%$ & & \\
\hline
\end{tabular}

\section{Qualitative findings}

\section{Respondents' gender and qualification}

Of the respondents, $61.54 \%$ were male and $38.46 \%$ were female. $46 \%$ had a BSc degree, $38.5 \%$ had a Diploma in nursing, $7.69 \%$ had a MSc degree, and $7.69 \%$ had a certificate in short health related trainings, (see Fig. 1). The respondents' mean number of months in their current position was 31.2.

The qualitative phase of the study attempted to uncover the reasons behind the referral of inappropriate cases by health centers to hospital care. Although there might be causal factors at both ends, this study scanned factors associated with the referral initiation site. As a result, it found three major themes and 11 categories. The following paragraphs describe each category.

Theme 1: capability of identifying appropriate cases for referral

Category 1: prior relationship with the health center

Health workers establish relationships with mothers during the antenatal (ANC) period. Interactions with mothers help health workers build good rapport with them and identify potential risks. Strong working relationships between health extension workers and midwives at the health center level facilitates to establishment of relationships with mothers. According to a respondent,

The first and fourth ANC are provided at health center level. The fourth ANC is used to provide further counseling the mother and her family about birth preparation and labor signs. As we do not have maternity homes, we try to make sure mothers are coming when they are close to labor. Even though we inform them to come late, if they come early, we find a room at the health center and allow them to stay there.

Category 2: high caseload at health center level

The health centers provide services to a designated catchment population of approximately 25,000 people. Most of the visited facilities provide services to a wider catchment population, and an increasing number of clients for institution-based care for various reasons. The number of health workers providing the services however did not match the rise in number of visits to the health centers and some health workers were not available due to having to attend meetings and training. According to a respondent, 
The caseload we encounter is not in accordance with our plan. People are coming from neighboring kebeles and woredas. Our plan is to provide services for 20 mothers per week, but we may see more than 20 and sometimes, up to 40 cases. When there is no case, we at least have ten cases.

Category 3: competent health workforce

The respondents stressed that health worker competence is related to their skills. According to them, short-term BEmONC in-service training, weekly peer mentorship and team consultations were available but limited to one staff member assigned to health a center and regular updates were not available. The respondents emphasized the impact of trainings on seeing improvements. According to a respondent,

I think we are referring the appropriate cases now. When we compare it to the last year's performance, there are lots of improvements. Last year, there were lots of referrals, but after the health workers got more experience and were trained in BEmONC, they easily diagnose and refer appropriate cases.

The lack of skills was also linked with wrong diagnosis for referrals, complications such as referred hypothermia in newborn cases, lack of clarity in referral slips, limited pre-referral management, and delays in referral. The respondents underlined that not having the required skills undermined providers' confidence and increased inappropriate care practices. One respondent stated,

The person who is referring may not be capable of diagnosing and writing referral slips. In some of the health centers where they have GPs, this doesn't occur as often. In other facilities however, it is not uncommon to find wrong information on the referral slips.

Category 4: logistical limitations leading to referrals

Due to logistical limitations, health center staff refer cases to the next level of the referral system, namely hospitals or a nearby facility. The reasons included shortage of power, lack of water, limited space and equipment, shortage of supplies and drugs, and laboratory reagents. The respondents reported that there was limited practice of introducing alternative power and water sources at health center level. Lack of laboratory services also forced health workers to rely solely on physical examination and thus empirical treatment, which led to unnecessary referral and practices at the health center level. A respondent described the situation and health worker frustration at health center saying,

We do not have any of the important supplies such as glucose, vitamin A, calcium gluconate, hydralazine, epileptic drugs, option B for HIV positive cases, and misoprostol. The shortage is because of budget limitations. It is annoying that because of these simple items, we are having to refer cases to other places.

Category 5: motivated health workforce

The respondents pointed out that many factors affected health worker motivation, including, availability of necessary materials and equipment and relationships with the community. The respondents indicated 
that low salaries, untimely payments of benefit packages, exclusion of some health workers from benefit packages, poor inter-professional support structures, and relationships among staff members affected their motivation. According to respondents,

There are lots of challenges. My pay is very low. I have a third-grade driving license, and I would earn more working as a driver for a private company than I currently do as a civil servant. I work long hours often a full 24 hours and don't receive benefit packages. They also say we are entitled to per diem payments when we go to hospitals but even that we don't receive on time.

The health center has a standard. We have 13 health workers currently. Some staff on maternity leave, and one is breast-feeding. Out of eight staff on active duty, five are expected to support health posts. How does anyone think the remaining health workers are able to provide the required quality services? With all these limitations, we still provide services $24 / 7$. Sometimes services are provided with no protective gear and we don't receive duty payments. On top of this, we only have one midwife who works with other health workers assigned to provide services in the delivery case team unit. However, as per the government guidance, the risk payment is only payable to the midwife. This affects the referral of services. In addition, the health center does not have a phone, so we are using our personal phones for which we don't receive any reimbursement

In relation to the health system support, the respondents added that ill equipped facilities, lack of essential drugs and supplies, management inability to establish good relationships among staff and impartiality of the facility management were factors influencing staff motivation at the health center level. According to respondents,

The management is not strong and it is biased. I expect the management to be fair to all. some of the decisions made in our day to day life are based on the individual's relationship with the management. Many of the staff are wanting to leave the facility early.

When talking to the health officers, they tell me that when they enter delivery case team unit, the midwives are not happy. The midwives say that the health officers should have fixed schedules. In addition, all the drugs and supplies in the delivery room are taken out on behalf of the midwives and the health officers may not be as cautious as they are. I think if they work in a committee and if we have a strong referral committee, they can easily work together.

The respondents also discussed the relationship they have with the community. Most of the respondents underlined that the main factor for their commitment to serve was their relationship with the community. The respondents indicated that praise from the community that followed quality care and outcomes, the willingness of the community to contribute to improved services, and their acceptance of the health workers' advice were key factors in their motivation.

The respondents indicated that health worker motivation was key to further improve the quality of service provided at the health center level. Some factors that affected motivation included long contact hours 
with clients, a clean work environment, sharing of costs borne by clients due to unavailability of drugs and supplies, strong follow up of the referred cases, and minimal or no negligent practices. According to respondents,

When they send the patient, if possible, they ask for the phone numbers of the recipient health workers at the hospital level. If they are unable to get that information, they record the phone number of the attendant and check the status of the referral. The follow up includes the place where they were referred to and tracks if there are further referrals. We reserve a copy of the referral paper and also have a referral registry to document the cases.

When we facilitate pregnant mothers' forums or when we accompany a mother during referrals at night, we may use our own money for transportation or may be forced to spend the night at other people's houses or at the hospital.

Theme 2: proper initiation of the referral process determines the outcome

Category 1 : knowledge of referral pathways

Referral by health workers or self-referral was determined by knowledge of referral pathways in the health system. The referral pathway, which was partly influenced by the availability of a referral directory, was affected by the community's knowledge of the available services at various levels of the health system. The respondents identified various factors that swayed mothers to go to hospitals directly: limited knowledge of services provided at health centers, advice from family and community members and private facilities, distance, and topography. According to a respondent,

Mothers residing in the town, bring their neonate here and we review the case. Together with the health extension workers, we are educating the community during pregnant mothers' forums about service availability.

Health worker knowledge of the services provided at neighboring health centers and referral hospitals was an important factor affecting the referral system. Regular update of the referral directory, including contact persons and available services in each referral facility, was identified an important factor in knowledge of the referral pathways. In addition, the respondents stated that proactive communication from the hospitals to health centers avoided unnecessary, multiple referrals due to unavailability of services or logistical problems at the referral hospitals. One respondent pointed out,

When the generator fails and depletes the reagents for certain investigations, we call the heads of the health centers so that they directly refer cases to the general hospital. This helps to reduce the delay which may happen due to multiple referrals.

Category 2: referral communication between facilities 
As part of the referral system, a health center is expected to assign a referral focal person and a hospital needs to establish a referral liaison office. The referral focal person is contacted whenever there is a referral. Despite this, high caseloads, minimal communication between facilities, lack of a dedicated room, limited functionality of referral committees, and no accountability framework especially during night shifts are obstacles to this function at the health center level. The limited functionality of the referral focal means there are gaps in the process of initiating a call before referrals take place and ensuring all the necessary documentation and assignment of health workers with the referral case are carried out. According to a respondent,

The health centers do not value the importance of the referral focal person. They merely assign the focal person for the sake of fulfilling the standard. This person should be informed before any referrals are conducted. If the person is not trained, they should undertake the proper training. This function is very important and should receive the needed attention from the woreda health office and the health center management. I know of people who have unnecessarily travelled from facility to facility for the sake of services and have died as a result to delays in treatment. If there is adequate communication before referrals, the outcomes may have been different.

Category 3: preparation for referrals

Preparation for referrals is a stepwise approach, which includes deciding on a referral, preparing a patient, preparing a referral slip and recording the case in the register. The decision on referrals should involve a team effort and the referral committee which should be operating at the health center level should make the decision. However, the timing of the referral cases and the availability of team members is a challenge to the functionality of this team. In addition, after the placement of general practitioners at the health center level, they are now the ones who decide on referrals. Patient preparation requires knowledge of the case and confidence in the established diagnosis. Moreover, proper counselling is also an important component to make sure the patient and her family accept the referral. Considering these factors, the respondents perceive the patient preparation required for referrals as insufficient. According to a respondent,

The pre-referral management is problematic. For example, for eclampsia cases [health workers] are expected to refer the patient after administering the loading dose, but they send the patient without any pre-referral management or writing it on the referral paper. Once the protein and blood pressure levels are raised, they are expected to start the loading dose and refer the patients. Additionally, when a mother experiences bleeding instead of administering IV they refer the case as if it is like other cases.

The availability of formats and registers, the competence of the health workers, caseloads, and availability of the referral committee influenced documentation of cases and referral paper preparations. A positive practice reported by the hospitals was that all referred cases had respective referral slips or papers prepared by health center staff. However, much of the information required was missing on some of the referral slips, especially when the health workers at health center level used plain paper. According to respondents, 
The person who is managing the case completes the referral slip and then I register the case in the referral register. The slip is filled in by the person who takes down the history of clients.

As [staff] are not adequately trained, we are taking steps to improve the completion of our referral slips. For example, if the case is diagnosed as perinatal asphyxia, they should at least record the APGAR score. Through repeatedly questioning staff on why they fail to complete the referral slips, we have learned that there may be capacity limitations and some have completely stopped using the slips.

Theme 3: functional cross-facility support platforms for better collaboration and coordination between facilities

\section{Category 1: feedback on referrals}

Feedback to the referring facility is a means of establishing communication between health centers and hospitals. When and how it is given has an impact on its application. Most of the health workers at the hospitals reported that they provided written or on-the-spot feedback to the referring health worker. Despite this, health centers have complained about lack of feedback in the system. Some of the respondents believe that most of the cases are referred for inappropriate reasons. The respondents gave the following reasons for the lack of referral feedback: overload of cases to provide written feedback, incomplete contact information of the referring health worker, limited follow up from the health center side, lack of health center commitment to work on the feedback, no health worker accompanying most referrals, use of inappropriate referral forms, and not trusting the competencies of health workers at the hospital level. According to a respondent,

We provide feedback some of which they may not accept as they may feel we are the same as they are in terms of qualifications. However, we have more experience and have worked with many other professionals who are of with a senior rank which ultimately means that we have better experience.

The health center staff, however, believe that lack of commitment on the part of the hospital staff is the reason that they do not receive feedback. Even when they provide feedback, the tone of communication is sometimes not appropriate. According to a respondent,

The tone in which feedback is given is always negative. This may be because they think they work at hospital level. For example, in a case of a prolonged labor, we meticulously assess clients and decide to refer some cases. Then, en route, due to the nature of the roads used, the position may change, or the labor may be hastened. When such cases reach the hospital, clients may deliver normally. In such instances, we get feedback that says, "you are sending us the inappropriate cases'. Sometimes, it is good to ask the patient herself and understand our efforts rather than concluding we are unwilling to provide the care here.

The referral focal person or the health center's head collects the referral feedback which is jointly reviewed by the delivery case team members. In some of the health centers, the feedback is used as an opportunity for coaching and filling in the missing materials which were a cause for some referrals. 
Respondents described meetings between staff at health centers, their respective hospital and woreda health office officials as opportunities where every stakeholder took on an assignment to improve persisting problems in the process of referrals. According to respondents,

Our relationship with the health centers should be properly guided. We need to establish a quarter-based meeting with them at a minimum. Recently we had a meeting with the $\mathrm{MCH}$ lead, referral focal person and midwives from the hospital and woreda health offices. We took samples from their referral feedback and held discussions with them.

Category 2: consultation and mentorship support

The relationship between health centers and hospitals can be strengthened further by initiating functional, technical support structures in the form of phone consultations and through the provision of either individual or group mentorship support to the health centers. The respondents stated that phone consultations are necessary in minimizing unnecessary referrals. According to a respondent,

When we have no one to consult here at the health center level, we call the hospital. These calls help us manage the cases here and avoid referrals. It also lets the hospitals know that they should prepare themselves to provide the services in case they are referred.

The respondents indicated that mentorship support improved health worker competence and reorganized service delivery platforms at health center level. As mentorship support requires advance preparation before the actual visit, it contributes to ensuring that health center problems are dealt with comprehensively and sends a message that, for any actions taken in the process of referred cases, the health center is accountable. This is a further opportunity for continued consultations between the health workers at the health center and hospital levels as well as an opportunity to present any administrativerelated problems to woreda health office representatives. One of the respondents described the process followed in providing group mentorship saying,

A pharmacist, an IESO, a lab technician, a GP, and quality officer went to a health center where the [IESO] conducted mass U/S screening. All of the visiting staff from the hospital supported the health center in various capacities. This was a great experience as it was helpful for the health center to receive feedback. Such visits are helpful in bridging gaps in differences of skill sets. The health system grapples with lack of accountability as [heath centers] have formal relations with the woreda, but not with hospitals. Moving forward, woreda level trainings can be a means of building strong communication between the institutions.

Category 3: functional service management committees

Various management-related committees have been established at both health center and hospital levels. The respondents identified the referral, MPDSR, and quality team committees among those that have a stake in the referral system. However, the functionality of those groups is either limited to one level or is known by very few in the system. According to a respondent, 
There is an MPDSR committee led by the quality unit which includes four midwives as part of the team. The committee analyzes cases to determine causes of the problems, and every team member is evaluated. The findings are then used to educate health workers at all levels. The analysis, however, does not include visits to the health center and homes of clients.

\section{Discussion}

Referral of patients, which is a transfer of responsibility in the provision of services and care of the client to another facility, happens for various reasons. One of the reasons is inappropriate referral which may be due to patient and facility related factors. As reported in this study, $65 \%$ of incidents were self-referral which is a common phenomenon in other parts of the world. Bypassing the primary contact facility is a common phenomenon in various non-regulated service delivery points. As a result of such factors, hospitals are increasingly tasked with the provision of care for normal deliveries that should have been managed at the primary care level (19).

The formal referral system includes the referring facility, community and transport, and the receiving facility. Factors related to these three components of the referral system may lead to inappropriate referrals. At the sending facilities, lack of prior interactions with clients during antenatal care, relationship with lower level health cadres, namely, health extensions workers during pregnant mothers' conferences at the community level, and wider population coverage can be considered as causal factors in relation to service organizations. In addition, due to high caseloads, limited competence among service providers, inappropriate practices during intrapartum care, and logistical problems, maternal and newborn related referrals were unnecessarily sent to primary hospitals. Similarly, the availability of technically competent health providers - which can be strengthened through in-service trainings - was identified as one of the factors for the provision of quality care in other studies (20) (21) (22). In addition, the perceptions of women on the health provider competence at BEmONC facilities also determined their choice of facility for care (20). High caseloads also compromise quality of time and care (23). Shortage of staff and inadequate skills mix often resulting in delayed care if not denial of care (24). A study in a Kabul maternity home in Afghanistan underlined the relationship between management and staff as a factor for staff employment and development opportunities (25). Lack of availability of the necessary equipment, drugs or important procedures at facilities were factors that negatively impacted quality of care (26).

The study found that knowledge of referral pathways determined the referral practices at the lower level of the system. A study on the referral system in North Central Nigeria also found that people with a good understanding of the referral system made 6.2 times more referrals than those with little knowledge or understanding of the concept of referrals (27). Communication between facilities is another important factor. Communication prior to referrals should be made by the referral focal person at health centers. Patient pre-referral preparation was not done well. Most of the referred cases had referral slips but information was incomplete and/or inaccurate. At some of the sites, the referral decision was made solely by the medical doctors rather than a committee. Ineffective referrals may happen due to 
inadequate referral communication and record maintenance, and absence of standard guidelines for referrals, facilities, and monitoring of referrals for obstetric care (28). In Ethiopia, communication between facilities is expected to happen and be facilitated through the liaison officer or referral coordinator of both sending and receiving facilities,(21). A study conducted by in Ethiopia found that only $31.4 \%$ of referrals were sent to the hospital with prior notification, there was poor pre-referral management of cases, $72.3 \%$ of prolonged/obstructed labor patients were transferred without intravenous access lines, $75.4 \%$ of patients with premature rupture of foetal membranes were not given antibiotics before referral, $79.5 \%$ of pre-eclampsia/eclampsia cases were not provided with magnesium sulphate as seizure prophylaxis, and $60.8 \%$ of foetal distress patients were referred without securing intravenous lines for resuscitation (29). In other counties incompleteness of the referral slips have been reported. A study on the quality of obstetric referral services for institutional births in Madhya Pradesh province, India found that most referred mothers had slips, but they contained inadequate details of treatment and progress of the labor (7). Similarly, compliance to referral guidelines was observed in India where the referral is accompanied by health providers (28).

Transporting the referred cases was a challenge. All the woredas visited had at least one ambulance for patient transportation. However, its availability was determined by the number of calls, who had called the driver, and other assignments given by the woreda health office. In several cases, public transport was an option if the client agreed. However, having ambulances available for some patients and using public transport for others was a matter for discussion between the community members and the health center management. In some cases, where health workers requested vehicles from government offices and neighboring woredas the ambulances were not well equipped for emergency management nor wellstaffed. In some woredas, emergency management technicians were assigned to each ambulance to provide the service while transporting the referred cases. However, health professionals at health center level accompanied cases based on caseloads and type of referred cases. In general, due to the reporting line being directed to the woreda rather than the hospital and no strong tracking system in place, ambulance services were poorly managed.

The readiness of the hospital to receive the referred clients and provide quality care was an important component of the referral system. Service availability was challenged by the capacity of the hospital to avail the necessary rooms and infrastructure, a highly trained workforce, and supplies and laboratory reagents. The number of cases admitted to the hospitals also compromised the quality of care. Reception to referred cases was dependent on the relationship with the sending facility and health workers. Communication between the sending and receiving facilities was not well established due to logistics, documentation factors, and patients coming unaccompanied by a health worker. Admitted cases were not properly monitored because of high caseloads, limited supervision support, and the poor follow up. In many cases, healthcare professionals tended to 'treat charts' rather than promote evidence-based practices while providing care. The quality of practice was challenged by insecurities in the work environment but was strengthened by good teamwork and the availability of consultation support. Beyond providing services at the hospital level, the primary hospitals failed to improve the capacity of 
health centers through mentorship support, communicating through positive feedback on referrals and linking hospital level and health center management structures.

Studies reported from Iran and India highlight that the governance system in institutions is very important. In rural Iran, the lack of feedback had a negative impact on the process of referrals and patient follow up (30). In India, lack of accountability and referral of minor cases that came directly to higher levels were among the factors affecting the referral feedback system (24).

The results presented should be interpreted considering the studies limitations. The researcher reviewed medical records to evaluate the completeness and outcome of care at the hospital level. The results may not be conclusive as some care may have been done, but not recorded. In addition, some cost items were programme related expenses and the costs may not be accurate.

\section{Conclusion}

An effective referral system is a critical component of the health system for the reduction of maternal mortality and morbidity due to obstetric complications (7) (Chaturvedi et al., 2014:1). The components of the referral system which includes the sending, transportation and receiving facilities should work together to make the system functional. On top of availing the required resources at the sending facilities, the relationship with the community is a critical factor in minimizing the high proportion of facility bypasses. In addition, the communication between facilities as well as availing appropriate transportation minimizes the time required to reach the appropriate facility and avoids unnecessary zig zag referrals. Even though the communication should be initiated by a designated body, the responsibility should not solely lie with the sending facility. There are multiple information gaps which hinder the effectiveness of referrals - all of which should be addressed at the transportation stage as well as at the receiving facilities. The outcome of care in this process should also be governed by a system which establishes and strengthens support as well as an accountability framework whereby all involved have knowledge and access to enhance the effectiveness of the referral system.

\section{Abbreviations}

\section{BEmONC}

Basic Emergency Obstetrics and Newborn Care; FMOH:Federal Ministry of Health; PHC:Primary Health Care; PHCU:Primary Health Care Unit; WHO:World Health Organization.

\section{Declarations}

\section{Ethics approval and consent to participate}

The proposal, survey methods and tools which guided this research were submitted for review and approval by the UNISA Department of Health Studies' Higher Degrees Committee. 


\section{Consent for publication}

Not Applicable

\section{Availability of data and materials}

All relevant data are within the paper and the data collection tool is also attached as a supporting Information files.

\section{Competing Interest}

none declared

\section{Funding}

The Authors received no funding.

\section{Acknowledgements}

The authors thank Heran Demissie for English language editing and data collectors and reviewers for their time in the data analysis.

\section{References}

1. United Nations Development Programme. Sustainable development goals, 2015-2030. New York: UNDP; 2012.

2. Pasha O, Saleem S, Ali S, Goudar SS, Garces A, Esamai F, et al. Maternal and newborn outcomes in Pakistan compared to other low and middle income countries in the Global Network's Maternal Newborn Health Registry: an active, community-based, pregnancy surveillance mechanism. Reprod Health. 2015;12(Suppl 2):15.

3. Traoré M, Arsenault C, Schoemaker-Marcotte C, Coulibaly A, Huchon C, Dumont A, et al. Obstetric competence among primary healthcare workers in Mali. Int J Gynecol Obstet. 2014 Jul;126(1):50-5.

4. Brenner S, De Allegri M, Gabrysch S, Chinkhumba J, Sarker M, Muula AS. The quality of clinical maternal and neonatal healthcare - a strategy for identifying "routine care signal functions.". PloS One. 2015;10(4):e0123968.

5. Rosen HE, Lynam PF, Carr C, Reis V, Ricca J, Bazant ES, et al. Direct observation of respectful maternity care in five countries: a cross-sectional study of health facilities in East and Southern Africa. BMC Pregnancy Childbirth. 2015;15:306.

6. Bradley S, Kamwendo F, Chipeta E, Chimwaza W, de Pinho H, McAuliffe E. Too few staff, too many patients: a qualitative study of the impact on obstetric care providers and on quality of care in 
Malawi. BMC Pregnancy Childbirth. 2015;15:65.

7. Chaturvedi S, Randive B, Diwan V, De Costa A Quality of Obstetric Referral Services in India's JSY Cash Transfer Programme for Institutional Births: A Study from Madhya Pradesh Province. Baradaran HR, editor. PLoS ONE. 2014 May 8;9(5):e96773.

8. Bhattacharyya S, Issac A, Rajbangshi P, Srivastava A, Avan BI. "Neither we are satisfied nor they"users and provider's perspective: a qualitative study of maternity care in secondary level public health facilities, Uttar Pradesh, India. BMC Health Serv Res. 2015;15:421.

9. Bosch X, Escoda O, Nicolás D, Coloma E, Fernández S, Coca A, et al. Primary care referrals of patients with potentially serious diseases to the emergency department or a quick diagnosis unit: a crosssectional retrospective study. BMC Fam Pract. 2014;15(1):75.

10. Blundell N, Clarke A, Mays N. Interpretations of referral appropriateness by senior health managers in five PCT areas in England: a qualitative investigation. Qual Saf Health Care. 2010 Jun 1;19(3):1826.

11. Creswell JW, Creswell JD. Research Design: Qualitative, Quantitative, and Mixed Methods Approaches.:388.

12. Bowling A. Research methods in health: investigating health and health services. Fourth edition. Maidenhead New York, NY: Open University Press; 2014. 512 p.

13. Leavy P. Research design: quantitative, qualitative, mixed methods, arts-based, and communitybased participatory research approaches. New York; London: Guildord Press; 2017. 301 p.

14. Bordens KS, Abbott BB. Research design and methods: a process approach. Tenth edition. Dubuque, IA: McGraw-Hill Education; 2018. 1 p.

15. Central Statistical Agency (CSA) [Ethiopia] and ICF. Ethiopia demographic and health survey, 2016. Addis Ababa: CSA and ICF; 2016.

16. Bruce N, Pope D, Stanistreet D. Quantitative methods for health research: a practical interactive guide to epidemiology and statistics. Second edition. Hoboken, NJ Chichester: Wiley; 2018. 545 p.

17. Merriam SB, Tisdell EJ. Qualitative Research: A Guide to Design and Implementation. 2016;371.

18. Polit DF, Beck CT. Nursing research: generating and assessing evidence for nursing practice. Tenth edition. Philadelphia: Wolters Kluwer Health; 2017. 784 p.

19. 10.1186/s13031-018-0137-1

Lagrou D, Zachariah R, Bissell K, Van Overloop C, Nasim M, Wagma HN, et al. Provision of emergency obstetric care at secondary level in a conflict setting in a rural area of Afghanistan - is the hospital fulfilling its role? Confl Health [Internet]. 2018 Dec [cited 2018 Apr 19];12(1). Available from: https://conflictandhealth.biomedcentral.com/articles/10.1186/s13031-018-0137-1.

20. Mahato PK. Determinants of quality of care and access to Basic Emergency Obstetric and Neonatal Care facilities and midwife-led facilities in low and middle-income countries. A Systematic Review. 2017;4:28.

21. $10.1186 / s 12884-015-0493-4$

Page 21/23 
Austin A, Gulema H, Belizan M, Colaci DS, Kendall T, Tebeka M, et al. Barriers to providing quality emergency obstetric care in Addis Ababa, Ethiopia: Healthcare providers' perspectives on training, referrals and supervision, a mixed methods study. BMC Pregnancy Childbirth [Internet]. 2015 Dec [cited 2018 Oct 8];15(1). Available from:

http://bmcpregnancychildbirth.biomedcentral.com/articles/10.1186/s12884-015-0493-4.

22. Yigzaw T, Carr C, Stekelenburg J, van Roosmalen J, Gibson H, Gelagay M, et al. Using task analysis to generate evidence for strengthening midwifery education, practice, and regulation in Ethiopia. Int $\mathrm{J}$ Womens Health. 2016 May;181.

23. Fujita W, Mukumbuta L, Chavuma R, Ohashi K. Quality of partogram monitoring at a primary health centre in Zambia. Midwifery. 2015 Jan;31(1):191-6.

24. Bhattacharya S. Health System Strengthening-Focussing on Referrals: An Analysis from India. JOJ Nurs Health Care [Internet]. 2017 Jun 30 [cited 2019 May 18];2(4). Available from: https://juniperpublishers.com/jojnhc/JOJNHC.MS.ID.555592.php.

25. Arnold R, van Teijlingen E, Ryan K, Holloway I. Understanding Afghan healthcare providers: a qualitative study of the culture of care in a Kabul maternity hospital. BJOG Int J Obstet Gynaecol. 2015 Jan;122(2):260-7.

26. Kant S, Kaur R, Malhotra S, Haldar P, Goel A. Audit of emergency obstetric referrals from a secondary level hospital in Haryana, North India. J Fam Med Prim Care. 2018;7(1):137.

27. Afolaranmi TO, Hassan ZI, Filibus DI, Al-Mansur UA, Lagi LA, Kumbak FD, et al. Referral System: An Assessment of Primary Health Care Centres in Plateau State. North Central Nigeria. 2018;6(1):5.

28. Singh S, Doyle P, Campbell OM, Mathew M, Murthy GVS. Referrals between Public Sector Health Institutions for Women with Obstetric High Risk, Complications, or Emergencies in India - A Systematic Review. Ho Y-S. editor. PLOS ONE. 2016 Aug;3(8):e0159793. 11.

29. PAUL'S HOSPITAL MILLENNIUM MEDICAL COLLEGE (SPHMMC)

11

\section{PRE-REFERRAL CARE AND APPROPRIATENESS}

7

Abdella MN, Meskelu J, Teklu AM, Bekele D. OBSTETRIC REFERRALS AT SAINT. PAUL'S HOSPITAL MILLENNIUM MEDICAL COLLEGE (SPHMMC): PRE-REFERRAL CARE AND APPROPRIATENESS. 2019;11(2):7.

30. Eskandari M, Abbaszadeh A, Borhani F. Barriers of Referral System to Health Care Provision in Rural Societies in Iran. J Caring Sci EISSN 2251-9920 [Internet]. 2013 [cited 2019 May 18]; Available from: http://journals.tbzmed.ac.ir/JCS/Abstract/JCS_20130829083612.

\section{Figures}




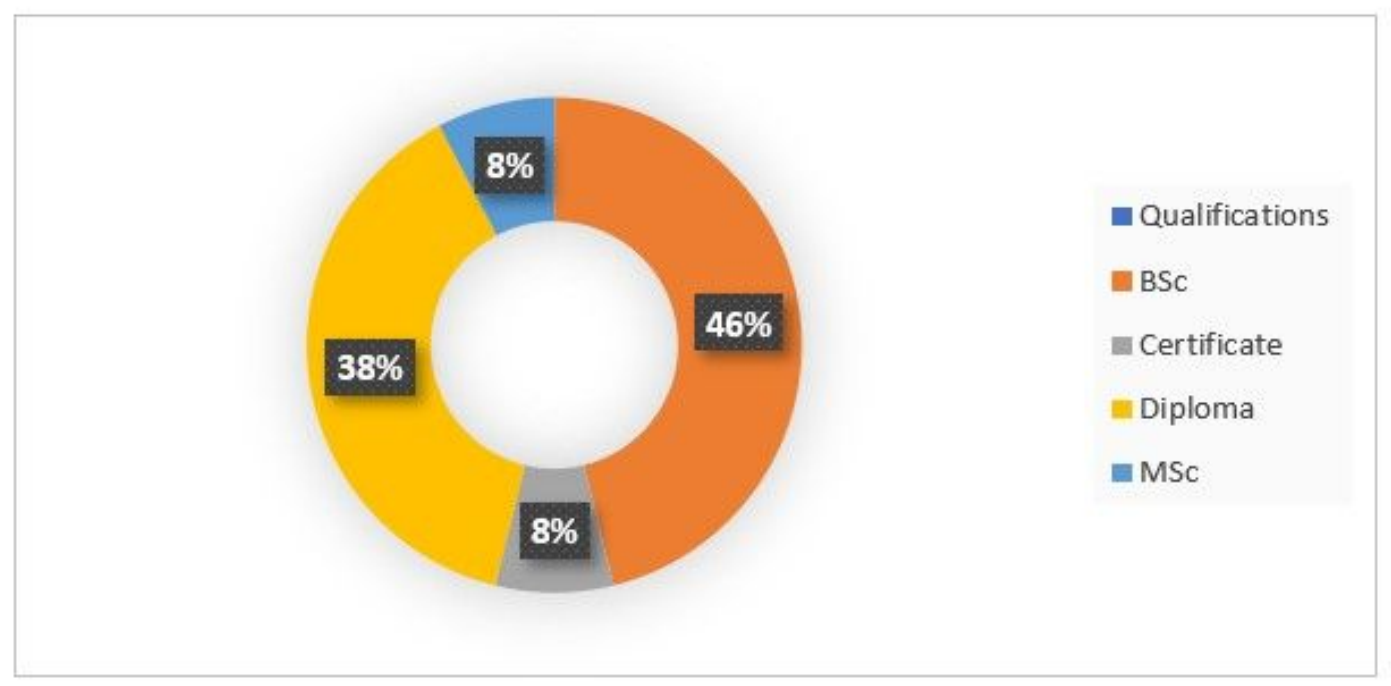

\section{Figure 1}

Key informants' qualifications

\section{Supplementary Files}

This is a list of supplementary files associated with this preprint. Click to download.

- Additionalfile2.docx

- Additionalfile1.docx 